\title{
Action myoclonus-renal failure syndrome
}

INSERM

\section{Source}

INSERM. (1999). Orphanet: an online rare disease and orphan drug data base. Action myoclonus-renal failure syndrome. ORPHA:163696

Action myoclonus-renal failure syndrome (AMRF) is a rare epilepsy syndrome characterized by progressive myoclonus epilepsy in association with primary glomerular disease. Patients present with neurologic symptoms (including tremor, action myoclonus, tonic-clonic seizures, later ataxia and dysarthria) that may precede, occur simultaneously or be followed by renal manifestations including proteinuria that progresses to nephrotic syndrome and end-stage renal disease. In some patients, sensorimotor peripheral neuropathy, sensorineural hearing loss and dilated cardiomyopathy are associated symptoms. 